\title{
Exploration on Modern Vocational Education System Promotion Strategies in Local Higher Vocational Colleges
}

\author{
Xiang Wu \\ Suzhou vocational University, Suzhou Jiangsu, 215104, China
}

\begin{abstract}
Keywords: Vocational education, Local higher vocational college, Modern vocational education system.
\end{abstract}

\begin{abstract}
In the field of Chinese education, modern vocational education system shows vocational expectations of local higher vocational college students for their own future career development, and it is also able to promote students in the learning process to gradually develop the habit of lifelong learning, and further enhance their comprehensive development, to meet constantly changing employment needs in the new era. Based on the nature and basic characteristics of modern vocational education system, this paper analyzes strategies of local higher vocational colleges to actively promote modern vocational education system, hoping to provide some support for current promotion of modern vocational education system in higher vocational colleges.
\end{abstract}

\section{Introduction}

With social development and progress of the new era, related elements of society have undergone some changes. Higher vocational colleges are impacted by social diversified culture and students' ideological complexity is gradually increased. Especially, complex source of students brings enormous difficulty for optimization of vocational education work in higher vocational colleges, but also puts forward new requirements on construction of modern vocational education system in higher vocational colleges. Therefore, higher vocational colleges, in order to obtain a better development in the new era, must strengthen the study on modern vocational education system, and combine with regional specialties to build the vocational education system able to properly adapt to college educational environment, to provide scientific modern vocational education guidance for students, and a solid guarantee for the sustained and healthy development of local higher vocational colleges.

\section{Main Connotation of Modern Vocational Education System in China}

Literally, from the vocabulary, it can be seen that construction of modern vocational education system contains three key words, namely modern, vocational education, and system, and modern and vocational education are the modifiers of system. Therefore, for in-depth understanding of this concept, the study should first clear connotation of system. Vocational education system often contains a large number of education elements closely related to vocational education, and these education elements can exist independently and also compose an organic whole by the interaction, serving for the development of vocational education. At the same time, analyze system design and system setting based on modern vocational education system. The most important point to actively build a modern vocational education system is combining with social needs to train social talents able to make some contribution to the socialist modernization construction. Therefore, specific studies can also take modern vocational education system as humane system for exploration. Under normal circumstances, in modern vocational education system, education department, education management department and training institutions are important parts of education system, and the ultimate goal of vocational education in higher vocational colleges is to help students to master particular vocational skills through the appropriate teaching guidance. Therefore, from this point of view, analysis on modern vocational education also can be referred to as vocational and technical education. In addition, in actively building modern vocational education system, there are two issues to be noticed, namely, the proper understanding of modernity and the emphasis on system 
construction. Only like this, it can really ensure the scientificity and modernity of modern vocational education in China, but also ensure that vocational education system can effectively promote realization of talent training goals of modern vocational education.

\section{Basic Features of Local Higher Vocational Education System}

\section{Strong modernity of guiding thought.}

In the construction of our local modern vocational education system, the guiding thought shows strong modernity. First, the construction thought has certain modern characteristics. In the construction of our local modern vocational education system, only the construction thought with sufficient modernity, can provide the right guidelines for the construction of local modern vocational education system. Currently, major development concept of our modern vocational education system is to highlight the idea of lifelong education and humanistic spirit in educational practice, and emphasize that education and teaching carried out can achieve the organic conversion between explicit and tacit knowledge ${ }^{[1]}$. Second, the industry has modernity. There is a very close relationship between construction of local vocational education and local economic construction, especially with the deepening development of reform and opening up, the role of local vocational education in promoting local economic development has gradually increased. At this stage, China is still in the initial development stage of socialism, construction of the socialist market economy with Chinese characteristics has a long way to go, and the implementation of innovative development strategy has gradually become an inevitable trend of economic development. Modern vocational education will be able to provide appropriate assistance for economic innovation and development, and technology-based, high-tech and inter-disciplinary talents it trains can provide a certain amount of human resources and support for the innovation and development of the local economy.

\section{Systematicness.}

In modern vocational education system, systematicness mainly includes three aspects:

First, openness. From the viewpoint of its own property, local vocational education system is a relatively open system, capable of communicating with outside enterprises and other education departments, and then to draw experience from the outside world in development, to change its shortcomings ${ }^{[2]}$. Under normal circumstances, the openness of local vocational education has embodied the following aspects, able to be open to all citizens at the local range; able to communicate and exchange with other education systems for coordinated development; mutually open industrial system, able to combine with talent demand changes due to social industry change, to make scientific adjustment on its own vocational education; open vocational education resources, able to be shared by means of Internet technology to provide certain facilities for students' vocational education learning.

Second, integrity. In the vocational education system, the so-called system is not a simple combination of relevant education elements in the system, but the unified whole under the influence of the nonlinear interaction, able to produce a greater education effect. Therefore, in construction of modern vocational education system, based on the analysis on individual elements and from the perspective of multiple factors, more in-depth exploration should be made, to find links between various elements, focus on whole system construction, and provide certain theoretical support for the development of local higher vocational colleges.

Third, dynamics. The whole education system will vary correspondingly with the change of external environment in modern vocational education system, and this change can be specifically divided into orderly and disorderly, balanced and unbalanced form. Therefore, dynamics is also an essential feature of modern vocational education system. Based on dynamic characteristics, study on modern vocational education system, first of all, should ensure system construction consistent with variation laws of corresponding industrial structure, to truly realize synchronized development of local vocational education and industrial structure adjustment. Secondly, for changes in demand for talents due to development of local industries, also it needs to update vocational education system to provide certain assistance for vocational education work in local higher vocational college. 


\section{Diversity of functions.}

In modern vocational education system, construction of local vocational education system is relatively complex, and the interaction between all relevant elements in the system is able to produce functional variability by means of non-linear combination. Our local vocational education system is mainly to have appropriate educational impact on society and educatees. For educatees, they can cultivate their own capabilities in modern vocational education system to meet the requirements of social positions on their overall quality, thus forming lifelong learning habit in the learning process, and getting a better future development. And from the social perspective, construction of modern vocational education system can, to a certain extent, have a corresponding positive impact on maintaining stability of citizen groups, and provide a lot of high-quality compound talents for the society, to promote communication of new knowledge and technologies within the society, and make appropriate contribution for the progress of social economy and socialist modernization.

\section{Modern Vocational Education System Promotion Strategies in Local Higher Vocational Colleges}

\section{Further strengthen overall management of government sectors on vocational education in China.}

In vocational education system, local vocational education work will inevitably involve a variety of stakeholders in the society, so that only strengthened co-ordination between various stakeholders by the government from a macro perspective can promote the establishment of harmonious relationship between various stakeholders, and provide proper protection for effective promotion of modern vocational education system. In specific practice, coordinate administration authority on vocational education, specify responsibilities and privileges taken and enjoyed in modern vocational education system by government education departments, schools and industry enterprises and various stakeholders, and then combine with specific content to coordinate the mutual relationship ${ }^{[3]}$. Meanwhile, the government should also focus on reasonable co-ordination of vocational education and industrial development, to really put vocational education system into local economic development planning, and strengthen the links of vocational education in higher vocational colleges and local economic development. In addition, co-ordination between vocational education and other higher education is also the key point. Only with the power of different education systems, local higher vocational colleges can be promoted to get a good development. Finally, reinforce the importance of school and corporate training co-ordination work, regard modern apprenticeship teaching as the breakthrough, and properly build enterprise training system in vocational education system in colleges and universities, to provide appropriate assistance for vocational education work.

Local higher vocational colleges should construct scientific talent training mode based on vocational goals.

Local higher vocational colleges should analyze special professions setting based on local education characteristics and from the personalized perspective, to train highly qualified personnel able to local economic development requirements ${ }^{[4]}$. In education system, higher vocational colleges are generally local universities, so the construction and development of local economy will inevitably have fundamental impact on the basic operation of higher vocational colleges, therefore, higher vocational colleges only take the regional economy development as a basis for profession setting in the process of development, and can truly reflect the prominent features of local vocational education, to meet the social demand for talents, and effectively enhance the scientificity and rationality of training mode. For example, with the need of industrial transformation and upgrading, six pillar industries in Suzhou area maintained rapid growth, including electronic information, equipment manufacturing, textile, light industry, metallurgy and chemical engineering. The new strategical pattern is formed, wherein, new industries and pillar industries coordinate together, and advanced manufacturing, modern services and information technology integrate and develop together. Training talents meeting social development is the main objective of vocational and technical education. 
Ensure scientificity of profession setting and personnel training mode according to talent training objectives.

\section{Scientifically set courses to construct diversified vocational education system.}

Scientifically setting courses to construct diversified vocational education system generally comprises two aspects. First, in terms of setting professional curriculum system, courses set by local higher vocational colleges must be able to reflect differences between higher vocational education, undergraduate education and intermediate vocational education, and meet the demands of socio-economic development and students' career development. Therefore, in particular curriculum setting, higher vocational colleges should pay attention to the organic combination of theoretical and practical teaching, and focus on training of students' comprehensive skills, formation of the sense of innovation and mastery of new technologies. At the same time, in order to implement scientific employment guidance for students, we should also keep abreast of the development trend of students after graduation, and take this as a basis for continuous adjustment and optimization of professional curriculum, to further enhance the scientificity and fitness of curriculum setting. Second, in terms of construction of social practice system, vocational education in higher vocational colleges should focus on training students' technical skills and further enhancing their employability and competitiveness in terms of practice so that based on in-depth understanding of theoretical knowledge, students can combine theory and practice, significantly improve their ability to analyze and solve problems, and provide a solid guarantee for their future overall development.

\section{Strengthen college-enterprise cooperation and promote international school.}

Based on the development of local vocational colleges, related government department clearly states that higher vocational colleges unable to carry out vocational education should take serving as the mission, students' employment as training objectives, and unswervingly follow the scientific development road combining industrial and academic research. Therefore, vocational education in higher vocational colleges should also, under the guidance and support of industrial and academic research cooperation department, build an integrated practice education base, to further strengthen the links between vocational education and enterprise. For example, local higher vocational colleges can set up training objectives and construct training mode with the help of enterprises, to ensure trained personnel can meet the needs of society ${ }^{[5]}$. At the same time, higher vocational colleges in the development process should also pay attention to learning from foreign successful experience in construction of modern vocational education system, and use international development of higher vocational colleges to promote modern vocational education system consistent with international standards, to truly realize modern development of higher vocational education. Only in this way, colleges can use the power of SFCRS (Sino Foreign Cooperation In Running Schools) for maintaining the advanced nature of modern vocational education to further enhance the fitness of higher vocational colleges graduates and social needs, to achieve personnel training objectives of higher vocational colleges, also tremendously boost construction of modern vocational education system and contribute to better development of our modern vocational education in the future.

\section{Conclusions}

In summary, our modern vocational education system has modernity, systematicness and diversified functions, plays an important role in good development of vocational education in higher vocational colleges. Therefore, to be based on local higher vocational colleges to actively promote modern vocational education system, firstly government and colleges should take appropriate measures, to provide appropriate support for promotion of modern vocational education system, also a solid security for the development of local vocational education, and make vocational education play a greater role in construction of local economic society. 


\section{References}

[1] Chen Baohua. Confusion and Reflection on Construction of Modern Vocational Education System, Education Exploration, 2015 (7): 101-103.

[2] He Zhen, Li Yuzhu. Building China Modern Vocational Education System Based on “International Education Standard Classification (2011)” , Capital Normal University (Social Science Edition), 2014 (3): 127-135.

[3] Xiao Kun, Chen Susong. Effective Convergence of Intermediate and Higher Vocation: An Exploration on Construction of Modern Vocational Education System - Taking Shunde Polytechnic College for Example, Education Forum, 2011 (30): 18-21.

[4] Nan Hai, Chen Juan. Modern Vocational Education System with Chinese Characteristics and Its Construction Strategies, Education Forum, 2015 (16): 45-48.

[5] Cao Ye, Liu Hongjie. Connotation of Modern Vocational Education System and Relevant Important Relations, Vocational and Technical Education, 2014, 35 (1): 5-9. 